\title{
Entitlement Attitudes Predict Students' Poor Performance in Challenging Academic Conditions
}

\author{
Donna Anderson ${ }^{1}$, Jamin Halberstadt ${ }^{1} \&$ Robert Aitken ${ }^{2}$ \\ ${ }^{1}$ Department of Psychology, University of Otago, New Zealand \\ ${ }^{2}$ Department of Marketing, University of Otago, New Zealand \\ Correspondence: Jamin Halberstadt, Professor, Department of Psychology, University of Otago, New Zealand. \\ E-mail: jhalbers@psy.otago.ac.nz
}

Received: February 24, 2013

Accepted: April 30, $2013 \quad$ Online Published: May 7, 2013

doi:10.5430/ijhe.v2n2p151

URL: http://dx.doi.org/10.5430/ijhe.v2n2p151

\begin{abstract}
Excessive entitlement - an exaggerated or unrealistic belief about what one deserves - has been associated with a variety of maladaptive behaviors, including a decline in motivation and effort. In the context of tertiary education, we reasoned that if students expend less effort to obtain positive outcomes to which they feel entitled, this should have negative implications for academic performance. We tested this hypothesis in a naturalistic experiment in a large course, in which students' self-reported entitlement attitudes (measured at the beginning of the semester), the idiosyncratic difficulty of the class, and several other individual difference variables associated with academic achievement (personal responsibility, frustration intolerance, and locus of control) were used to predict final exam performance. As expected, greater entitlement was associated with poorer final exam marks, particularly among students for whom the class was objectively challenging. Although no other personality variable qualified the interaction, the extent to which students accepted responsibility for their performance mediated the main effect of entitlement, while external locus of control independently predicted poor exam performance.
\end{abstract}

Keywords: Entitlement, Academic performance, Effort, Personal responsibility, Frustration intolerance, Locus of control

\section{Introduction}

Psychological entitlement refers to individuals' beliefs about what they deserve, and how they should be treated by others (Levin, 1970). It represents a stable set of attitudes that feed expectations and influence people's perceptions of themselves, others and the world (Kriegman, 1983). Among other things, possessing a sense of entitlement helps people to reject unfair treatment and gives them confidence to expect and claim good treatment from others. As such, psychological entitlement is considered both necessary and essential to human growth (Levin, 1970).

However, excessive entitlement can lead to maladaptive behavior. Excessive entitlement is characterised by an exaggerated sense of self-importance that, according to Farmer (1999), produces "an unreasonable expectation of favorable treatment without assuming reciprocal responsibilities" (p. 56). By virtue of these unreasonable expectations excessively entitled individuals may rely too heavily on others to achieve desirable outcomes, and to overlook or minimize the need for their own effort in achieving them. Thus, while a minimal sense of entitlement may be motivating, excessive entitlement may be demotivating, resulting in a reduction in effort and performance, particularly when challenges to success are encountered. The current study explores the implications of entitlement attitudes in the context of higher education.

\section{Literature Review}

Despite a growing awareness of the varied and problematic nature of some entitlement attitudes, and the belief that excessive entitlement attitudes are on the rise (Campbell, Bonacci, Shelton, Exline, \& Bushman, 2004; Capron, 2004; Moses \& Moses-Hrushovski, 1990), there has been very little research on entitlement that goes beyond a mere description of the construct. For example, previous research has associated entitlement with negative personality traits, such as egocentrism (Kriegman, 1983; Rothstein, 1977), irrationality (Billow, 1997; Kriegman, 1983), selfishness (Kriegman, 1983), aggression (Campbell et al., 2004; Kerr, 1985) and insensitivity (Foster, 2000; Grey, 1987), but has not explored how entitlement attitudes might influence effort and performance. 
Some research in the education literature has also highlighted the negative effects of students' excessive entitlement attitudes on work performance and personal responsibility (Morrow, 1994). Some educators have argued that an over-emphasis on self-esteem development - such as educators giving indiscriminate praise to students, without linking the praise to legitimate effort - may have inadvertently boosted students' sense of entitlement in unproductive ways, which has resulted in a perceived shift of responsibility for academic achievement from the student to the provider (Morrow, 1994).

According to Greenberger, Lessard, Chen and Farruggia (2008), many educators complain that students expect high grades in exchange for just moderate effort, have unrealistic expectations towards academic staff, or demand that lecturers accommodate their needs. Such expectations seem to represent feelings of excessive entitlement; indeed, the term "academic entitlement" has been used to refer to students" expectations of desired outcomes in an academic environment that do not realistically match their own efforts (Chowning \& Campbell, 2009).

Although no research has established a definitive link between entitlement attitudes and academic performance, a number of studies have found links between entitlement and other personality traits that make such a link plausible. For example, one important aspect of entitlement is the failure to take responsibility for achieving one's goals (Chowning \& Campbell, 2009), a factor that could explain the reluctance to exert effort to attain those goals. Indeed, Hwang (1995) attributes the general decline in American students' educational performance to failures of personal responsibility, "a culture which produces professional victims who refuse to take responsibility for their own actions" (p. 489). In the context of classroom performance, such reluctance may translate into decreased effort, particularly when a task requires more effort than expected.

Another plausible reason why entitled students might struggle academically is that they are easily frustrated when effort is required and/or are particularly intolerant of such frustration. Indeed, "frustration intolerance," defined as "an inability or unwillingness to persist in an activity due to the unpleasant feelings associated with the task" (Wilde, 2012), has been associated with procrastination in academic contexts (Harrington, 2005b, 2006), which in turn could result in lower grades. To the extent that highly entitled students are also highly intolerant of frustration, they may fail to thrive in the face of academic challenges that require unexpected effort in order to be overcome.

A third aspect of entitlement that could produce decreased academic effort is an individual's "locus of control" (LOC) - the degree to which an individual believes that external influences (as opposed to they themselves) control their lives (Gordon et al., 1977; Parker, 1999; Rotter, 1990) - which many studies have associated with task effort and completion. For example, Spector (1982) found that LOC predicted effort in an organizational setting, with "internals" (i.e., participants with an internal LOC) being more pro-active and motivated than "externals." In a study investigating why students dropped out of long distantance education programs, Parker (1999) found LOC to be a key predictor of course work completion and attrition, in theory because students who had an internal locus of control were more motivated to achieve their academic goals than students with an external locus of control. Furthermore, entitlement, which theoretically reflects the attitude that achievement should come from external sources rather than from internal effort (Kerr, 1985), may be associated with an external locus of control, thereby providing a psychological mechanism for entitled students' reluctance to put in the necessary effort to overcome an academic challenge.

\section{Purpose of the Study}

The primary purpose of the current study was to examine the relation between entitlement, academic challenge, and academic performance in vivo. A large sample of business students enrolled in the same course were surveyed at the beginning of the semester, and their trait-level entitlement was used to predict their academic performance on the final exam. Assuming that academic performance is at least partly a function of effort, students' performance should be negatively related to their entitlement attitudes, particularly when they perceive an academic situation to be challenging. A secondary purpose of the study was to explore other individual differences associated with both entitlement attitudes and effortful behavior that might explain (mediate) or qualify (moderate) the relationship between them.

We hypothesized that entitlement attitudes would be negatively related to academic performance, particularly for students who found the class difficult. We also tested in separate models (but did not make a priori predictions about) the mediating and moderating effects of personal responsibility, frustration intolerance, and locus of control, to determine whether one or more of these facets would either explain or exacerbate any observed entitlement effects. 


\section{Method}

\subsection{Participants}

Participants were recruited from a large undergraduate Commerce course ("Marketing and Consumption"; enrolment: 683 ) at the University of Otago, $51 \%$ male, and approximately $80 \%$ of European descent. At the conclusion of the first lecture, students were invited, but not compelled, to participate in the study by completing a questionnaire and giving permission for their internal assessments and exam result to be included in the data collection process. The students were told that the aim of the research was to explore how various personality measures were related to transition into university life and levels of effort shown. Two hundred and ninety-three students volunteered.

\subsection{Materials}

Trait entitlement was measured using the Psychological Entitlement Scale (PES, Campbell et al., 2004). The PES consists of 9 items (e.g., "I honestly feel I'm just more deserving than others"). The measure has good internal consistency $(>.80)$ and test-retest reliability of . 72 and .70 over 1-month and 2-month time periods (Campbell et al., 2004).

Personal responsibility was measured using the 10-item Student Personal Responsibility Scale (SPRS-10; Singg \& Ader, 2001), originally developed to measure students' "acceptance of personal responsibility in their day-to-day student living." The scale shows acceptable test-retest reliability and construct validity, as well as positive correlations with academic performance and retention (Singg \& Ader, 2001). Items include "I turn all my assignments in on time" and "I miss class often" (reverse scored).

Frustration intolerance was measured using the 7-item entitlement facet of Harrington's Frustration Discomfort Scale (2005a; FDS), which measures, with good internal consistency and discriminant validity, intolerance of unfairness and frustrated gratification (Harrington, 2005a). Scale items include "I can't tolerate criticism especially when I know I'm right" and "I can't stand having to wait for things I would like now."

Locus of Control was measured using the ten-item version of the Rotter scale (LOC; Rotter, 1954), which includes items such as "Many bad things in one's life happen just because of bad luck," and "Most of the time, a person cannot rise above his or her background." The validity and usefulness of the LOC scale has been established in a variety of academic and non-academic domains and meta-analyses (e.g., Findlay \& Cooper, 1983).

The measures (among others, not used in the current study) were assembled into a single questionnaire, always in this order: PES, FDS, LOC and SPRS. Participants indicated their agreement with each item on the same 1-7 scale, anchored at "Strong Disagreement," "Moderate Disagreement," "Slight Disagreement," "Neither Agreement nor Disagreement," "Slight Agreement," "Moderate Agreement," and "Strong Agreement." Responses on each measure, reverse-scored where necessary, were summed such that higher scores reflect greater entitlement, higher frustration discomfort, external locus of control, and greater sense of responsibility.

The two major assignments in the course, a "critical reflection" on the portrayal and influence of a particular brand, and an oral "deconstruction" of a pair of advertisements, together representing $45 \%$ of the overall course grade, were used to estimate the idiosyncratic challenge that the paper represented to students (see Results). Students' grades on the (essay-based) final exam were used as the primary dependent measure of academic performance.

\subsection{Procedure}

At the conclusion of the first lecture session for the first semester, students were invited to participate in the study, and a questionnaire packet with an accompanying instruction sheet was provided to those students who indicated their wish to participate. Students completed the questionnaire at their own pace and returned it to the experimenter as they left the lecture room.

\section{Results}

At the end of the term, course marks were accessed with the assistance of the course coordinator. Participants who did not complete the questionnaire in full $(\mathrm{N}=36)$, or who received no credit for one or both of the internal assessments ( $\mathrm{N}=17)$, were not included in any analyses. Descriptive statistics for all measured variables appear in Table 1. 
Table 1. Descriptive statistics and correlations among main dependent variables

\begin{tabular}{llllllllll}
\hline Variables & $\alpha$ & Mean & SD & 2 & 3 & 4 & 5 & 6 & 7 \\
\hline 1. PES & .87 & 29.97 & 10.02 & $-.18^{*}$ & $.50^{* *}$ & $.43^{* *}$ & -.10 & -.09 & $-.13^{*}$ \\
2. SPRS & .76 & 50.47 & 8.76 & & $-.15^{*}$ & $-.29^{* *}$ & $.18^{*}$ & $.25^{* *}$ & $.31^{* *}$ \\
3. FDS & .83 & 29.10 & 7.59 & & & $.42^{* *}$ & .01 & .07 & -.01 \\
4. LOC & .67 & 35.18 & 7.68 & & & & -.10 & -.13 & $-.19^{*}$ \\
5. Assign. 1 (\%) & & 73.43 & 11.08 & & & & & $.40^{* *}$ & $.36^{* *}$ \\
6. Assign. 2 (\%) & & 80.68 & 8.63 & & & & & & $.28^{* *}$ \\
7. Final exam (\%) & 66.75 & 17.93 & & & & & &
\end{tabular}

Notes: $\mathrm{N}=240 ; \quad \mathrm{PES}=$ Psychological Entitlement Scale; SPRS=Student Personal Responsibility Scale; FDS=Frustration Discomfort Scale; LOC=Locus of Control. ${ }^{* *} p<.001 ; * p<.05$.

In order to estimate objectively the difficulty individual students faced in the course, marks on the first assignment were used to predict performance on the second assignment in a regression analysis. The first assignment explained $16 \%$ of the variance in the second $(\beta=.40, p<.001)$, and the unstandardized residual of the model was used as the measure of "challenge". Thus, more negative numbers reflected worse performance on a student's second assignment than was statistically predicted by his or her first assignment, and therefore a relatively more challenging situation.

To test the primary hypothesis that entitlement attitudes would predict worse academic performance, particularly among students for whom the class was challenging, entitlement attitudes (PES scores), academic challenge, and their interaction (with main effects centered) were entered simultaneously in a multiple regression predicting final exam scores. As seen in Table 2, the analysis revealed independent effects of all predictors: stronger entitlement attitudes, and poorer than expected performance during the semester, were both (weakly) associated with lower final exam marks. The interaction was explored by correlating entitlement and exam scores separately for students who performed better versus worse than expected (reflected by a positive or negative "challenge" score). As predicted, among participants doing worse than expected (and therefore presumably finding the class more challenging), greater entitlement predicted worse performance on the final exam, $\mathrm{r}(112)=-.29, \mathrm{p}<.005$. Among participants doing better than expected, PES and final exam performance were unrelated, $\mathrm{r}(128)=.02, \mathrm{p}>.8$.

Table 2. Multiple regression of final exam scores on entitlement, challenge and their interaction

\begin{tabular}{llllll}
\hline Variables & $B$ & $S E B$ & $\beta$ & $t$ & $p$ \\
\hline PES & -.221 & .113 & -.124 & -1.96 & .051 \\
Challenge & .305 & .143 & .135 & 2.14 & .034 \\
PES X Challenge & .034 & .013 & .17 & 2.71 & .007
\end{tabular}

Note: $\mathrm{R}^{2}=.07 ; \mathrm{F}(3,236)=5.59, \mathrm{p}=.001 ; \mathrm{PES}=$ Psychological Entitlement Scale; Challenge=unstandardized residual of second assignment regressed on the first.

To examine the role of personal responsibility in these effects, the regression analysis was re-run, entering SPRS and its associated two and three way interactions (i.e., with challenge and PES) simultaneously in a second step (see Table 3). The analysis revealed a main effect of SPRS, such that students taking greater responsibility for their actions obtained higher final exam marks. Neither the main effect of entitlement nor of challenge was significant with SPRS effects in the model, though the interaction of the two remained a reliable predictor. Given this result, we proceeded to test the mediating effect of personal responsibility in the PES-exam and challenge-exam relationships, by generating bias-corrected $95 \%$ confidence intervals for the indirect effects using 10,000 bootstrap samples (Preacher \& Hayes, 2008). The resulting confidence intervals did not include zero in either analysis (-.19 and -.02 for PES; .05 and .24 for challenge), indicating that personal responsibility statistically explains the main effects of both entitlement and challenge on exam performance.

The same approach was used to examine the role of frustration discomfort and (in a separate regression model) locus of control (see Tables 4 and 5). 
Table 3. Multiple regression of final exam scores on entitlement, challenge, personal responsibility and their interactions

\begin{tabular}{llllll}
\hline Variables & $B$ & $S E B$ & $\beta$ & $t$ & $p$ \\
\hline PES & -.13 & .11 & -.07 & -1.13 & .26 \\
Challenge & .20 & .14 & .09 & 1.38 & .17 \\
PES X Challenge & .04 & .01 & .21 & 3.15 & .002 \\
SPRS & .60 & .13 & .29 & 4.58 & $<.001$ \\
SPRS X PES & -.001 & .01 & -.005 & -.08 & .94 \\
SPRS X Challenge & .01 & .02 & .05 & .80 & .42 \\
SPRS X Challenge X PES & $<.01$ & $<.01$ & .01 & .14 & .89 \\
\hline
\end{tabular}

Note: $\mathrm{R}^{2}=.15 ; \mathrm{F}(6,233)=6.86, \mathrm{p}<.001 ; \mathrm{PES}=$ Psychological Entitlement Scale; Challenge=unstandardized residual of second assignment regressed on the first; SPRS=Student Personal Responsibility Scale

Table 4. Multiple regression of final exam scores on entitlement, challenge, frustration discomfort and their interaction

\begin{tabular}{llllll}
\hline Variables & $B$ & $S E B$ & $\beta$ & $t$ & $p$ \\
\hline PES & -.28 & .13 & -.16 & -2.17 & .03 \\
Challenge & .30 & .15 & .13 & 1.98 & .05 \\
PES X Challenge & .04 & .01 & .18 & 2.51 & .01 \\
FDS & .19 & .18 & .08 & 1.06 & .29 \\
FDS X PES & .04 & .01 & .17 & 2.68 & .01 \\
FDS X Challenge & -.02 & .02 & -.07 & -1.03 & .30 \\
FDS X Challenge X PES & $<-.01$ & $<.01$ & -.06 & -.92 & .36 \\
\hline
\end{tabular}

Note: $\mathrm{R}^{2}=.08 \mathrm{~F}(6,233)=3.34, \mathrm{p}=.004$; PES= Psychological Entitlement Scale; Challenge=unstandardized residual of second assignment regressed on the first; FDS=Frustration Discomfort Scale

Table 5. Multiple regression of final exam scores on entitlement, challenge, locus of control, and their interaction

\begin{tabular}{llllll}
\hline Variables & $B$ & $S E B$ & $\beta$ & $t$ & $p$ \\
\hline PES & -.13 & .13 & -.07 & -1.03 & .31 \\
Challenge & .33 & .15 & .14 & 2.14 & .03 \\
PES X Challenge & .03 & .01 & .14 & 2.14 & .04 \\
LOC & -.43 & .17 & -.19 & -2.65 & .009 \\
LOC X PES & .01 & .02 & .06 & .89 & .38 \\
LOC X Challenge & .04 & .02 & .13 & 1.87 & .06 \\
LOC X Challenge X PES & $<-.01$ & $<.01$ & -.07 & -.93 & .35
\end{tabular}

Note: $\mathrm{R}^{2}=.11 \mathrm{~F}(6,233)=4.51, \mathrm{p}<.001 ; \mathrm{PES}=$ Psychological Entitlement Scale; Challenge=unstandardized residual of second assignment regressed on the first; LOC=Locus of Control

Neither FDS nor LOC effects significantly changed the coefficients associated with entitlement, challenge, or their interaction (with one exception). However, in the model using FDS an interaction emerged between PES and FDS, due to the fact that entitlement predicted lower exam scores only among participants relatively low (i.e., below the median score) in frustration intolerance, $r(109)=-.33, p<.001$, and not for those relatively high, $r(119)=-.04$, $p>$.6. In the model using LOC, LOC emerged as a main effect, such that internal locus of control predicted better exam outcomes, though a marginal interaction with challenge suggested that this was true only among participants who found the class more difficult than expected $r(112)=-.34, p<.001$ versus $r(128)=-.05, p>.05$. The main effect of PES was no longer significant with LOC in the model, and bias-corrected $95 \%$ confidence intervals $(-.25$ and -.03) for the indirect effects did not include zero, indicating that LOC mediated the effect of PES on exam 
performance. However, a follow-up analysis using SPRS and LOC as simultaneous mediators revealed only an independent indirect path through SPRS (CIs=-.19 and -.02 for SPRS; - .18 and .03 for LOC).

\section{Discussion}

If many accounts of Western educators are to be believed, modern education has bred a culture of entitlement. According to Greenberger et al. (2008), many educators complain that students expect high grades in exchange for just moderate effort, have unrealistic expectations towards academic staff, or demand that lecturers accommodate their needs. Despite such concerns, and the belief that students' sense of entitlement is greater than in the past (Campbell, Bonacci, Shelton, Exline, \& Bushman, 2004; Capron, 2004; Moses \& Moses-Hrushovski, 1990), there is little evidence that entitlement attitudes, if they are indeed on the rise, are associated with measureable academic outcomes. Should educators be concerned that students who feel entitled to good grades are less likely to actually achieve them?

The current study suggests that they should. Given that excessive entitlement is characterized by "an unreasonable expectation of favourable treatment without assuming reciprocal responsibilities" (Farmer, 1999, p. 56), we expected that highly entitled students would fail to exert effort when it is required. In the context of the current study, "required effort" was operationalized as the statistical trajectory of students' performance in class. Clearly, a decline in performance over the course of the semester signals that more effort is required to succeed on the final exam, and because highly entitled students are less motivated to make that effort, we predicted that their final exam scores would suffer. These hypotheses were confirmed: entitlement attitudes predicted exam performance, but only among students for whom the class was challenging. Indeed, challenged participants scored about one half point worse on the final exam for each additional point in their PES scores, or about five points worse per standard deviation.

The study also provided an opportunity to examine other personality measures that in theory could moderate or mediate the predicted effect of entitlement attitudes on academic achievement, thereby providing insight into individual vulnerabilities that might hinder academic success. Three plausible factors were considered - personal responsibility, frustration intolerance, and locus of control - each of which has been associated with academic performance in previous research. Somewhat surprisingly, none of the three factors qualified the interaction between entitlement and challenge, suggesting that the latter may be quite robust to individual variability.

Nevertheless, a number of other interesting findings emerged from the inclusion of these third variables in our models:

Personal responsibility. The degree to which students accepted responsibility for their own academic outcomes not only predicted exam performance, but also statistically explained the main effect of entitlement (though, importantly, not the interaction of entitlement and challenge). That is, our data suggest that higher entitlement might lead to poorer performance via the decreased sense of personal responsibility it engenders. Interestingly, personal responsibility also mediated the main effect of challenge: participants performing better than expected in the class took greater personal responsibility for those outcomes, which in turn explained better performance in the final exam. Though unexpected, the effect makes sense from the perspective of classic attribution theory (e.g., Heider, 1944). For self-serving purposes, individuals tend to attribute positive outcomes to internal causes (e.g., intelligence, effort) and negative outcomes to external causes (teacher bias, difficulty of the test; Snyder, Stephan \& Rosenfield, 1976; see also Miller \& Ross, 1975). Our data suggest that such attributions might have unanticipated downstream effects on subsequent academic tasks.

Frustration intolerance: The results for frustration intolerance were harder to interpret, as FDS interacted with entitlement, such that the negative relation between entitlement and performance was evidenced only for those with a high tolerance for frustration. It was hypothesized that, if anything, a low tolerance for frustration would exacerbate entitlement effects, which perhaps derive in part from frustration over having to exert unexpected effort, and the fact that it does not, tentatively falsifies the hypothesis that entitlement effects are due to frustration per se. It is not clear, without replication and further data, what positive conclusions should be drawn about the role of frustration intolerance in entitlement-driven academic deficits, so we will avoid further speculation here.

Locus of control: Consistent with previous research (Parker, 1999), participants who reported a more internal locus of control (i.e., who tended to view personal outcomes as the result of their own effort or other internal causes) were more academically successful than those who attributed outcomes to forces outside of their control. Furthermore, like personal responsibility, locus of control mediated the effect of entitlement on performance, although only the former was reliable when the two mediators were modelled simultaneously. Moreover, a marginal interaction with idiosyncratic class difficulty suggests that academic LOC effects emerge only in the face of a challenge - in this case, 
when a student was faced with declining grades. Though a novel finding, the interaction makes sense given previous research in attribution theory. In particular, Wong and Weiner (1981) found that participants asked attribution ("why") questions about the outcome of a hypothetical exam more often when the exam mark was negative and/or unexpected. In the current study, "challenged" participants, by definition, faced outcomes that were both negative and unexpected, and so these students would have been most likely to draw attributional inferences about their performance - and to suffer or benefit from them in the subsequent exam.

\section{Conclusion}

Our findings represent an important early step in understanding how entitlement attitudes relate, at least predictively, to real academic outcomes. Our data, though correlational, suggest that students who have a stronger sense of entitlement are less motivated to exert effort to achieve positive academic outcomes, so when such effort is required (i.e., when a course is unexpectedly challenging) their academic performance will suffer relative to students who do not take good performance as a right. The results also have practical significance, for example for identifying students early who may have an exaggerated sense about what they are entitled to in the academic environment, and specifically what they can legitimately expect from their academic provider and lecturers in the way of support. Clearly outlining these issues may help counteract unrealistic expectations that sooner or later will be challenged, and prepare students for the personal resilience and responsibility required to achieve academic success, which attitudes of excessive entitlement negate.

\section{References}

Billow, R. M. (1997). Entitlement and counterentitlement in group psychotherapy. The International Journal of Group Psychotherapy, 47, 459-474.

Campbell, W. K., Bonacci, A. M., Shelton, J., Exline, J. J., \& Bushman, B. J. (2004). Psychological Entitlement: Interpersonal consequences and validation of a self-report measure. Journal of Personality Assessment, 83(1), 29-45. http://dx.doi.org/10.1207/s15327752jpa8301_04

Capron, E. W. (2004). Types of pampering and the narcissistic personality trait. Journal of Individual Psychology, 60(1), 76-93.

Chowning, K., \& Campbell, N. J. (2009). Development and validation of a measure of academic entitlement: Individual differences in students' eternalized responsibility and entitled expectations. Journal of Educational Psychology, 101(4), 982-997. http://dx.doi.org/10.1037/a0016351

Farmer, S. A. (1999). Entitlement in codependency. Journal of Addictive Diseases, 18(3), 55-69. http://dx.doi.org/10.1300/J069v18n03_06

Findlay, M. J. \& Cooper, H. M. (1983). Locus of control and academic achievement: A literature review. Journal of Personality and Social Psychology, 44, 419-427. http://dx.doi.org/10.1037/0022-3514.44.2.419

Foster, D. (2000). Entitlement as explanation for perpetrators' actions. South African Journal of Psychology, 30(1), $10-16$.

Gordon, D. A., Jones, R. H., \& Short, N. L. (1977). Task persistence and locus of control in elementary school children. Child Development, 48, 1716-1719. http://dx.doi.org/10.2307/1128543

Greenberger, E., Lessard, J., Chen, C., \& Farruggia, S. P. (2008). Self-entitled college students: Contributions of personality, parenting, and motivational factors. Journal of Youth Adolescence, 37, 1193-1204. http://dx.doi.org/10.1007/s10964-008-9284-9

Grey, A. (1987). Entitlement: An interactional defense of self esteem. Contemporary Psychoanalysis, 23, 255-262.

Harrington, N. (2005a). The Frustration Discomfort Scale: Development and psychometric properties. Clinical Psychology and Psychotherapy, 12, 374-387. http://dx.doi.org/10.1002/cpp.465

Harrington, N. (2005b). It's too difficult! Frustration intolerance beliefs and procrastination. Personality and Individual Differences, 39(5), 873-883. http://dx.doi.org/10.1016/j.paid.2004.12.018

Harrington, N. (2006). Frustration intolerance beliefs: Their relationship with depression, anxiety, and anger, in a clinical population. Cognitive Therapy and Research, 30, 699-709. http://dx.doi.org/10.1007/s10608-006-9061-6

Heider, F. (1944). Social perception and phenomenal causality. Psychological Review, 51, 358-374. http://dx.doi.org/10.1037/h0055425 
Hwang, Y. G. (1995). Student apathy, lack of self-responsibility and false self-esteem are failing American schools. Education 115, 484-490.

Kerr, N. J. (1985). Behavioral manifestations of misguided entitlement. Perspectives in Psychiatric Care, 23(1), 5-15. http://dx.doi.org/10.1111/j.1744-6163.1985.tb00251.x

Kriegman, G. (1983). Entitlement attitudes: Psychosocial and therapeutic implications. The Journal of the American Academy of Psychoanalysis, 11(2), 265-281.

Levin, S. (1970). On psychoanalysis of attitudes of entitlement. Bulletin of the Philadelphia Association for Psychoanalysis, 20, 1-10.

Miller, D. T. \& Ross, M. (1975). Self-serving biases in the attribution of causality: Fact or Fiction? Psychological Bulletin, 82, 213-225. http://dx.doi.org/10.1037/h0076486

Morrow, W. (1994). Entitlement and achievement in education. Studies in Philosophy and Education, 13(1), 33-47. http://dx.doi.org/10.1007/BF01074084

Moses, R., \& Moses-Hrushovski, R. (1990). Reflections on the sense of entitlement. Psychoanalytic Study of the Child, 45, 61-78.

Parker, A. (1999). A study of variables that predict dropout from distance education. International Journal of Educational Technology, 1(2), 1-10.

Preacher, K. J., \& Hayes, A. F. (2008). Asymptotic and resampling strategies for assessing and comparing indirect effects in multiple mediator models. Behavior Research Methods, 40, 879-891. http://dx.doi.org/10.3758/BRM.40.3.879

Rothstein, A. (1977). The ego attitude of entitlement. The International Review of Psychoanalysis, 4, 409-417.

Rotter, J. B. (1954). Social learning and clinical psychology. New York, NY: Prentice Hall. http://dx.doi.org/10.1037/10788-000

Rotter, J. B. (1990). Internal versus external control of reinforcement. American Psychologist, 45 (4), 489-493. http://dx.doi.org/10.1037/0003-066X.45.4.489

Singg, S., \& Ader, J. A. (2001). Development of the Student Personal Responsibility Scale-10. Social Behavior and Personality, 29(4), 331-336. http://dx.doi.org/10.2224/sbp.2001.29.4.331

Spector, P. E. (1982). Behavior in organizations as a function of employee's locus of control. Psychological Bulletin, 91(3), 482-497. http://dx.doi.org/10.1037/0033-2909.91.3.482

Snyder, M. L., Stephan, W. G. \& Rosenfield, D. (1976). Egotism and Attribution. Journal of Personality and Social Psychology, 33, 435-441. http://dx.doi.org/10.1037/0022-3514.33.4.435

Wilde, J. (2012). The relationship between frustration intolerance and academic achievement in College. International Journal of Higher Education, 1(2). http://dx.doi.org/10.5430/ijhe.v1n2p1

Wong, P. T. P., \& Weiner, B. (1981). When people ask "Why" questions, and the heuristics of attributional search. Journal of Personality and Social Psychology, 40(4), 650-663. http://dx.doi.org/10.1037/0022-3514.40.4.650 